\title{
RESEARCH
}

Open Access

\section{Outcomes from the medication assisted treatment pilot program for adults with opioid use disorders in rural Colorado}

Claudia R. Amura ${ }^{1 *}$ (D), Tanya R. Sorrell ${ }^{1,2,3}$, Mary Weber ${ }^{1}$, Andrea Alvarez ${ }^{4}$, Nancy Beste ${ }^{5}$, Ursula Hollins ${ }^{6}$ and Paul F. Cook

\begin{abstract}
Background: As Colorado ranked among the top nationally in non-medical use of opioids, a pilot medication for opioid use disorder (MOUD) program was developed to increase the number of NPs and PAs providing MOUD in order to bring this evidence- based treatment to 2 counties showing disproportionally high opioid overdose deaths. Over the first 18 months, the MOUD Pilot Program led to 15 new health care providers receiving MOUD waiver training and 1005 patients receiving MOUD from the 3 participating organizations. Here we evaluate patient centered clinical and functional outcomes of the pilot MOUD program implemented in 2 rural counties severely affected by the opioid crisis.
\end{abstract}

Methods: Under state-funded law (Colorado Senate Bill 17-074), three rural agencies submitted de-identified patient-level data at baseline ( $N=1005)$ and after 6 months of treatment $(N=190,25 \%)$ between December 2017 and January 2020. The Addiction Severity Index, PhQ9 and GAD-7 with McNemar-Bowker, and Wilcoxon Signed Rank tests analysis were used to measure patient outcomes across after participation in the program. .

Results: Patients in treatment reported using less heroin ( $52.1 \%$ vs $20.4 \%$ ), opioids ( $22.3 \%$ vs $11.0 \%$ ), and alcohol (28.6\% vs $13.1 \%$, all $P<0.01)$. Patients reported improved health $(53.4 \%$ vs. $68.2 \%, P=0.04)$, less frequency of disability ( 8.69 vs. $6.51, P=0.02)$, symptoms ( $29.8 \%$ vs $21.3 \%)$, pain ( $67.5 \%$ to 53.6$)$, worry $(45.3 \%$ vs $62.3 \%)$, anxiety (49.7\% vs $23.2 \%)$, depression ( $54.1 \%$ vs $23.3 \%$, all $P<0.02$ ) after treatment.

Conclusions: This study shows decreased substance use, improved physical and mental health, and reduced symptoms after 6 months of MOUD. Although more research on retention and long-term effects is needed, data shows improved health outcomes after 6 months of MOUD. Lessons learned from implementing this pilot program informed program expansion into other rural areas in need to address some of Colorado' major public health crises.

Keywords: Medication-assisted treatment for opioid use disorder, Pain, Rural, Community settings, Patient centered outcomes

\footnotetext{
* Correspondence: claudia.amura@cuanschutz.edu

'University of Colorado College of Nursing, 13120 E. 19th Ave, Aurora, CO 80045, USA

Full list of author information is available at the end of the article
}

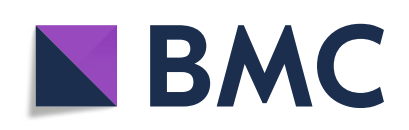

(- The Author(s). 2021 Open Access This article is licensed under a Creative Commons Attribution 4.0 International License, which permits use, sharing, adaptation, distribution and reproduction in any medium or format, as long as you give appropriate credit to the original author(s) and the source, provide a link to the Creative Commons licence, and indicate if changes were made. The images or other third party material in this article are included in the article's Creative Commons licence, unless indicated otherwise in a credit line to the material. If material is not included in the article's Creative Commons licence and your intended use is not permitted by statutory regulation or exceeds the permitted use, you will need to obtain permission directly from the copyright holder. To view a copy of this licence, visit http://creativecommons.org/licenses/by/4.0/. The Creative Commons Public Domain Dedication waiver (http://creativecommons.org/publicdomain/zero/1.0/) applies to the data made available in this article, unless otherwise stated in a credit line to the data. 


\section{Background}

Opioid use disorders (OUD) are a national public health crisis due to the rise in both illicit and prescribed opioid use, as well as opioid-related mortality and morbidity [1]. There were almost 50,000 ( 70\% of all drugs) opioid overdose deaths in 2019 [2].

Opioids were involved in 49,860 overdose deaths in 2019 (70.6\% of all drug overdose deaths). Opioid use has been shown to associate with comorbid mental health issues, risk behaviors, and economic instability [3, 4], posing a huge burden for people with addictions, their families, and their communities.

The increasing number of cases and overdose deaths has been particularly hard in rural areas that also face disproportionate service gaps $[5,6]$. In Colorado, recent reports showed that 1:10 residents live in places with no access to treatment and many in remote rural areas have to travel over 30 miles to seek treatment [6] Although (half million Coloradans reported that they or a love one struggle with prescription pain medications or nonprescribed opioids, 95,000 reported not accessing treatment in 2019 [7]. This underscores the urgency of overcoming access barriers to OUD treatment in remote underserved areas.

Medication for Opioid Use Disorder (MOUD) is an evidence-based practice that combines medication and behavioral interventions [8]. Despite demonstrated efficacy in survival and treatment retention, MOUD services are rarely available in rural areas, leading to inconsistent access to care [9].

Nurses, as one of the largest groups of health service providers in the United States, are in a unique position to care for people with OUD in underserved rural areas $[10,11]$. After nurse practitioners became eligible in 2016 to prescribe opioid-based buprenorphine for the treatment of OUD, Colorado Senate Bill 17-074 was introduced as a community-based effort to fund a pilot program bringing Nurse Practitioner (NP) and Physician Assistant (PA)-led MOUD to rural Colorado communities. Between December 2017 and June 2019, the University of Colorado College of Nursing (CU Nursing) worked to engage rural clinics, train providers, and implement a MOUD pilot program in Pueblo and Routt counties. The program added 15 nurse practitioners and physician assistants to the MOUD workforce and served 1005 new patients during the first 18 months [12]. Although the legislation was designed primarily to increase access, CU Nursing and community stakeholders also wanted to know to what extent the program was helping patient's lives, including mental and physical health, social functioning, employment, disability, and legal system involvement. Here we report patient-centered outcomes after participating in the MOUD program in one of three rural clinics for at least 6 months. Lessons learned from this pilot informed further development of MOUD services in rural Colorado.

\section{Methods \\ Settings and program implementation}

The pilot program was designed to implement MOUD at health care sites in two rural counties, Pueblo and Routt, which had OUD-related overdose and death rates higher than state and national averages. Three community clinics received funding between 2017 and 2019: a methadone clinic that added buprenorphine to its services, a community mental health center that expanded its existing MOUD services, and a startup clinic that provided MOUD as part of a multidisciplinary pain services [12]. Service delivery began on December 1, 2017.

\section{Participants}

The clinics in this study serve a racially and ethnically diverse patient population with a mix of health insurance and living experiences. As reported elsewhere [12], patients seeking MOUD services were over 18 years old and met OUD clinical criteria. Prior to starting MOUD, patients underwent a clinical interview by trained staff and consented to receive treatment and to have their clinical information aggregated as part of program evaluation. Patients could refuse providing some information without consequences to their treatment. All procedures were designed to comply with ethical standards for human subject's studies, although this study was determined by the Colorado Multiple Institutional Review Board to be non-human subject research (protocol \#19-2217).

\section{Procedure and instruments}

As part of the program evaluation, MOUD service data were collected between 2017 and 2020. Process data were collected monthly from each of the program sites during the duration of the pilot and for up to 6 additional months for patient follow up. Aggregated agencylevel data were analyzed based on monthly reports about services provided, successes, and barriers for implementation and patient retention, and used to answer process evaluation questions [12].

De-identified patient data collected at study entry from 1005 clients included self-reported demographics, medical history, and substance use information. Assessment of treatment outcomes was conducted 6 months after treatment initiation using the validated Addiction Severity Index (ASI), 5th edition [13] to capture past-month drug use, overall health, social functioning, and physical and psychological symptoms. Additional items from the ASI 6th edition [14] were used to evaluate coexisting medical and behavioral health conditions, pain, recent emergency department use or inpatient hospitalization, 
and other social determinants of health including employment and legal problems. Patients also completed the Patient Health Questionnaire (PHQ-9) to measure depressive symptoms [15] (strong reliability and correlation with substance use, Cronbach's alpha $=0.90$ [16 and the Generalized Anxiety Disorder scale (GAD-7) for anxiety [17], and (IRR $=0.85)$ Cronbach's alpha $=0.91$ [18]) in substance using populations.

Data were collected at each site by a case manager or intake worker and entered into the REDCap electronic data management system [19] hosted at the University of Colorado Anschutz campus. Aggregated, de-identified data were extracted for analysis and assessed for data integrity at the end of data collection by CU Nursing researchers. The patient-level REDCap data set had a high rate of missing data, which reflects the voluntary nature of the collection and the clinics' focus on delivering services rather than on data collection, as well as patient loss to follow up.

\section{Statistical analysis}

All statistical tests were conducted on de-identified aggregated data using SPSS version 26 (IBM Corporation). Demographic characteristics were summarized using descriptive statistics, and outcome variables were checked for normal distribution. For continuous variables, mean values and standard errors are presented. Percentages were tabulated for categorical data. Pre-Post changes in client-centered outcome variables were evaluated using McNemar $(\mathrm{Y} / \mathrm{N})$ or McNemar Bowker tests for nominal variables, and $t$ tests and Wilcoxon Signed Rank Test for normally and non-normally distributed interval-level variables, respectively. Wilcoxon Signed Ranks tests were also performed for confirmatory sensitivity analysis.

\section{Results}

\section{Patient characteristics}

Of 1005 inductions, 288 (28.7\%) were still in treatment 6 months after the start of MOUD, and 177 had 6-month substance use data with various degrees of completeness by variable. Complete data on substance use on evaluable subjects (those who started treatment and completed both the baseline and follow-up assessments, $\max n=169$ ) were used for the MOUD outcome analysis. Baseline patient characteristics in this study are presented in Table 1 . Overall, demographics were similar between patients who remained in treatment for at least 6 months (evaluable patients) and those lost to follow-up (non-evaluable, also comparable to the whole population) [7]. On average, evaluable patients were adults 25 to 44 years old (61.6\%), not married (78.9\%), White (57.0\%) or Hispanic (36.7\%), had completed approximately 12.5 years of education (48.5\% had completed high school), and had Medicaid insurance coverage (86.9\%).

About half of the patients had been unemployed during the last 3 years (52.6\%), with no differences between evaluable and non-evaluable patients. About a third of patients presented to the clinic based on a judicial system referral or were worried about legal problems (30\%). About 1 in 3 patients reported having had some outpatient (32.0\%) or inpatient detoxification (27.3\%) treatment previously, and $2.37 \%$ had not attempted any other treatment methods in the past, with no differences between evaluable or nonevaluable patients. Most patients (83.1\%) initially reported that their current decision to get treatment was self-prompted. However, compared to patients who started but were lost to follow up, evaluable patients were less likely to be court-ordered $(14.1 \%$ vs $7.1 \%, P=0.01)$ or to be on parole or probation (25.2\% vs $11.1 \%, P=0.01)$. All patients had a history of use opioids and/or heroin, and many also used other substances (32-38\%); most were in poor to moderate health $(80.2 \%)$ and suffered moderate to extreme pain (65\%, see Fig. 1).

\section{Changes in clinical outcomes after MOUD treatment}

Pre-post treatment changes on measures regarding substance use were assessed among the 169 evaluable patients with complete baseline and 6-month data on substance use (Fig. 1). Those who were still in treatment reported less heroin use in the past month than at start, with $52.1 \%$ vs $20.4 \%$ of patients reporting any heroin use, and $37.1 \%$ vs $5.4 \%$ using heroin daily. A Wilcoxon Signed-Rank Test indicated that the median post-test ranks were statistically different than the pre-test ranks, Median 1.0 (IQR 30.00), vs 0.0 (IQR 20.00) (Supplemental Table 1), all $P<.01$. They also reported less use of prescription opioids $(22.3 \%$ vs $11.0 \%$ of patients reported any opioid use, with $11.7 \%$ vs 3.5 using opioids daily, $P<.01$, and a reduction in the number of days, $P=$ .021). After 6 months, patients also reported significantly less alcohol use $(28.6 \%$ vs $13.1 \%$ of patients reported any drinking), with $4.40 \%$ of participants who drank daily at baseline vs $0.6 \%$ post treatment. Patients also reported drinking less days per month (Median 0.0 vs 0.0 vs days, $P<.001)$. Interestingly, use of cannabis increased significantly (19.1 to $30.2 \%$ of daily use, $P<.02$, Median number of days 0.0 vs $0.0, P=.028$ ), although the percent of people reporting any use did not change $(49.1 \%$ vs $43.0 \%$ ), which could indicate a compensatory pain management strategy given that $41 \%$ of patients at baseline had indicated marijuana use for pain management. The sensitivity analysis for substance use (Supplemental Table 1) yielded similar trends in terms of both significance and directionality. Patients reported overall using 
Table 1 Baseline demographics of patients in the Colorado MOUD Pilot Program

\begin{tabular}{|c|c|c|c|}
\hline Characteristic & Non-Evaluable ${ }^{a} \mathrm{~N}(\%)$ & Evaluable N (\%) & $P$ \\
\hline Gender & $N=723$ & $N=174$ & .21 \\
\hline Female & $341(47.2)$ & $86(48.6)$ & \\
\hline Male & $368(50.9)$ & $87(49.2)$ & \\
\hline Other & $1(0.1)$ & $1(0.1)$ & \\
\hline Race/Ethnicity & $N=723$ & $N=177$ & .33 \\
\hline White non-Hispanic & $368(50.9)$ & $101(57.0)$ & \\
\hline Hispanic & $310(42.9)$ & $65(36.7)$ & \\
\hline Other & $24(1.0)$ & $11(4.0)$ & \\
\hline Age & $N=714$ & $N=176$ & .06 \\
\hline 18-24yrs. old & 96 (13.3) & 19 (10.7) & \\
\hline 25-34 yrs. old & $302(41.8)$ & $69(39.0)$ & \\
\hline 35-44 yrs. old & $189(26.1)$ & $40(22.6)$ & \\
\hline 45-54 yrs. old & $88(12.2)$ & $28(15.8)$ & \\
\hline 55-64 yrs. old & $32(4.4)$ & $17(9.6)$ & \\
\hline Over 65 yrs. old & $7(0.9)$ & $3(1.7)$ & \\
\hline Health Insurance & $N=363$ & $N=171$ & .53 \\
\hline Medicaid only & $278(76.6)$ & $136(83.4)$ & \\
\hline Medicare only & $12(3.3)$ & $10(6.1)$ & \\
\hline Medicaid + Medicare & $15(4.1)$ & $6(3.5)$ & \\
\hline Private & $24(6.6)$ & $8(4.7)$ & \\
\hline Other & $7(1.9)$ & $0(0)$ & \\
\hline None & $27(7.4)$ & $8(4.5) \mathrm{P}$ & \\
\hline Employment in the last 3 yrs & $N=362$ & $N=168$ & .37 \\
\hline Full time & $101(27.9)$ & $57(32.8)$ & \\
\hline Part time & $71(19.6)$ & $25(14.5)$ & \\
\hline Unemployed & $190(52.5)$ & $91(52.6)$ & \\
\hline Marital status & $N=364$ & $N=171$ & .77 \\
\hline Married & $73(20.3)$ & $36(21.0)$ & \\
\hline Widowed, Separated, or Divorced & $107(29.4)$ & $58(33.9)$ & \\
\hline Never Married & $184(50.5)$ & $77(45.0)$ & \\
\hline \multicolumn{4}{|l|}{ Previous treatment } \\
\hline No previous OUD treatment & $120(33.1)$ & $47(27.3)$ & .67 \\
\hline Reason to start treatment ${ }^{b}$ & $N=355-553$ & $N=167-183$ & \\
\hline Self-motivation & $453(82.0)$ & $151(83.1)$ & .87 \\
\hline Court-order & $56(14.1)$ & $12(7.1)$ & $P<.01$ \\
\hline On parole or probation & $93(25.2)$ & $19(11.1)$ & $P<.01$ \\
\hline
\end{tabular}

Demographics describe patient characteristics at the start of treatment $(n=190)$ collected by three participating rural clinical sites. Missing data due to lack of selfreporting varied by item, from $\sim 6 \%$ for age and race/ethnicity to $>50 \%$ for employment or substance use specification; actual counts per variable are noted ${ }^{a}$ Evaluable patients are those who started the MOUD treatment and completed both baseline and follow-up surveys, as contrast with non-evaluable patients had an induction but withdrew or were lost to follow-up and thus did not have follow-up data regarding substance use. ${ }^{b}$ Reasons for start treatment are all independent variables and do not add up to $100 \%$

less sedatives (26\% vs $6.0 \%)$, cocaine $(9.0 \%$ vs $1.8 \%)$ both $P<.01)$, and very small reduction methamphetamine or barbituratesany day use after treatment $(P<.05)$.

Health changes after 6 months of treatment are shown in Fig. 2. The percent of patients reporting moderate to severe pain or discomfort diminished significantly after treatment $(67.5$ to $53.6 \%, P<.01)$. Patients also showed significant reduction in anxiety $(49.7 \%$ at baseline vs $23.2 \%$ post treatment showed moderate to high anxiety), based on GAD-7 average scores decreasing significantly 


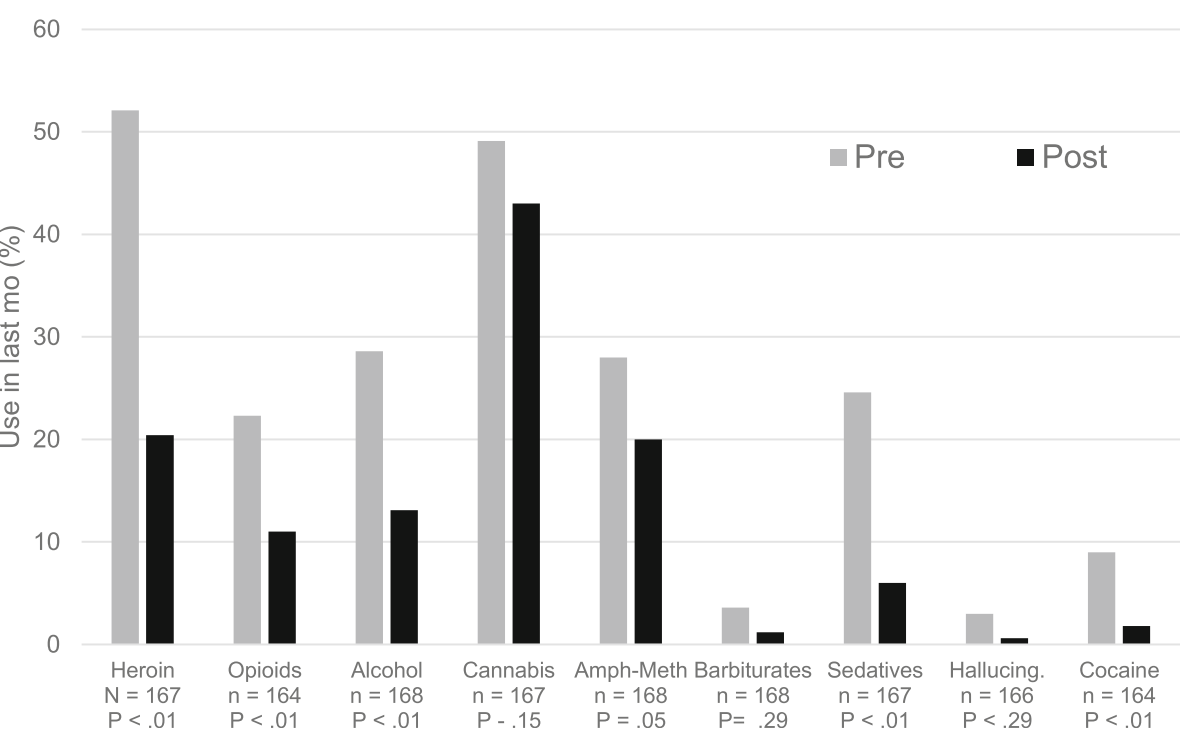

Fig. 1 Changes in substance use after participation in the Colorado MOUD Pilot Program. Figure shows the percentage of patients reporting any day of use of the indicated substances in the previous month, both at baseline (pre) and after 6 months of treatment (post), with $P$ values for changes from baseline (Mc Nemar-Bowker; $<.05=$ statistically significant). Aggregated data from patients $(n=168)$ in 3 rural sites participating in the MOUD program is shown. Missing data due to lack of self-reporting varied by item and actual counts per paired variable are noted. AmphMeth $=$ Amphetamine - methamphetamine.

after treatment $(10.5 \pm 7.4$ vs $6.1 \pm 5.4, P<.01)$, which corresponds to a shift in clinical interpretation from "moderate anxiety" to "mild anxiety." Major depressive levels paralleled this trend $(54.1 \%$ vs $23.3 \%$ of patients scored moderate to high depression, $P<.01$ ), with an average clinical shift from "moderate depression" to "mild depression" (scores: $10.5 \pm 7.15$ vs $6.2 \pm 5.83$, $P<.01)$. The frequency of symptoms slightly but significantly changed (daily: $29.8 \%$ vs $21.3 \%$; no symptoms: $35.4 \%$ vs $44.8 \%$; overall change $P=.03$ ). There were fewer patients reporting they were unable to carry out normal activities because of physical or medical

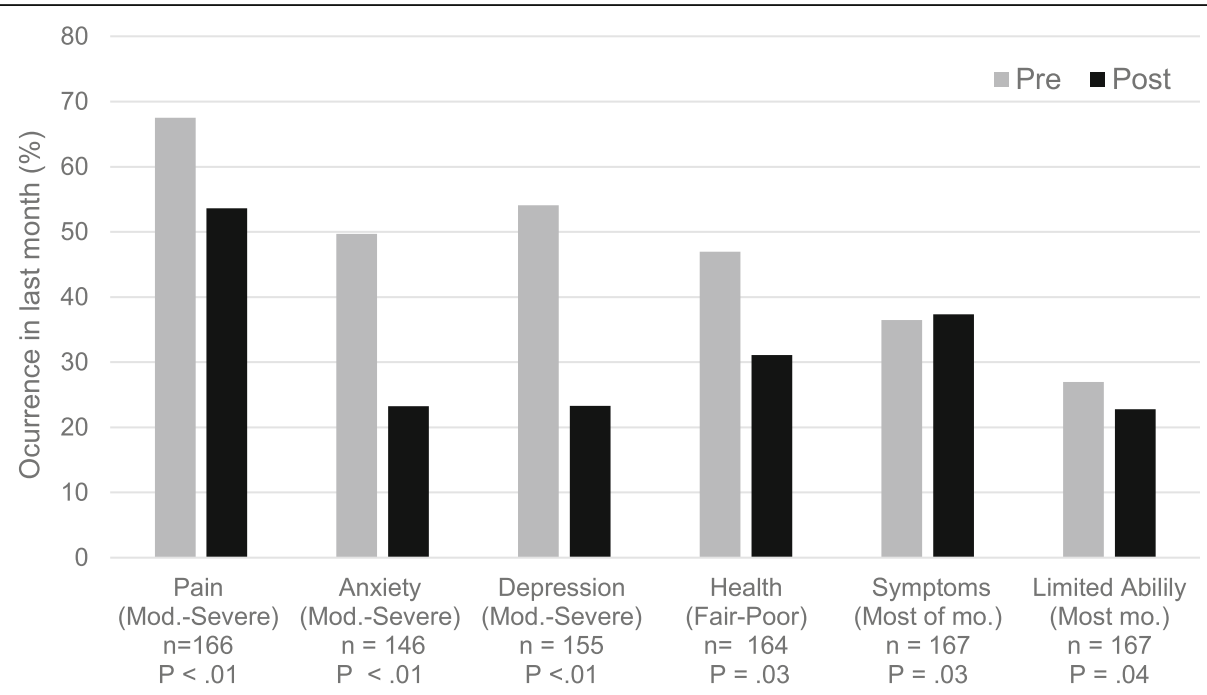

Fig. 2 Changes in Physical and Mental Health after MOUD treatment. Figure shows the percentage of patients reporting the following health related issues during the past month, at (pre) and after 6 months of treatment (post), with $P$ values for overall changes from baseline: Pain $=$ moderate to severe pain or discomfort; Anxiety (GAD-7 scores for moderate to severe anxiety); Depression (PHQ-9 scores corresponding to moderate to severe depression); Poor Health (less than good health or poor to fair); Symptoms (physical or medical symptoms over half of the month); Limited ability (unable to carry out normal activities because of physical or mental symptoms during over half of the month). $P$ values shown changes from baseline (Mc Nemar-Bowker; <.05 = statistically significant, evaluable data, $n=167$ ). Missing data due to lack of selfreporting varied by item and actual counts per paired variable are noted. 
problems after treatment for most days in the month after treatment $(26.9 \%$ vs. $22.7 \%, P=.04)$ or any day in the month $53.3 \%$ vs $43.1 \%, P=0.04)$. 3). Changes in scores were confirmed with sensitivity analyses $(P<.01$ for the nonparametric tests).

\section{MOUD treatment and changes in social determinants of health}

Baseline data on factors associated with OUD, including employment, health care utilization, and legal system involvement, demonstrated that the program reached a patient population with substantial life problems related to OUD. After 6 months of MAT, patients had slightly but not significantly fewer emergency room visits in the prior month, $P=.10$ (Fig. 3). Likewise, there were no changes for the patients who reported spending days in jail on the previous month, $P=.89$, or being on parole, although those numbers were very low at the start of treatment, leaving limited room for improvement. There were no changes in the percentage of patients who worked on the previous month $(61 \%$ vs $56 \%, P=0.29)$ or the number of days worked .

Fig. 4 shows patients' perceptions of their health and social issues from baseline to 6 months after treatment start. After 6 months, patient concerns regarding their overall health increased after treatment, going from 45.3 to $62.3 \%$, moderately to extremely concerned $(P=.02)$; however, their perception of the importance of continuing treatment did not have a significant change $(61.1 \%$ vs $68.1 \%$ reporting at least moderate importance, $P=$ .12). On the other hand, patients seemed less concerned about work issues after treatment (overall $43.6 \%$ vs $29.0 \%$ were concerned, $P=.06)$ or the need for workrelated counseling (drop from 20.2 to $12.9 \%$ in moderately to highly concerned, $P=.02$ ). There were no significant changes in concerns about legal issues.

\section{Retention in care}

Monthly reporting and community of practice debriefs revealed several efforts dedicated to program implementation, as well as challenges to patient retention in care. As reported in detail elsewhere [12], clinicals sites engaged community partnerships which were essential to recruit patients However, this take significant effort to develop, and despite outreach efforts (partnership with jails, hospitals, churches, local health care providers), stigma regarding substance use and associated mental health issues remains major treatment barriers in rural areas and requires strategies to build support for treating patients and a main focus for program continuation.

Retaining patient in care was a major problem faced by participating clinics, although clinics attempted to partially address it by using multi-modal treatment that includes behavioral and supportive interventions as well as medication. Likewise, clinical sites revealed main challenges to track patients who drop out of treatment, and dealing with mobile populations, homeless, although some cycling in and out of care seems to be normal, and having an opendoor policy to welcome back patients who want to resume treatment seems essential, and discussed the need to dedicate resources to maintain a patient registry and to track individual patients who fall out of care. Reimbursement is

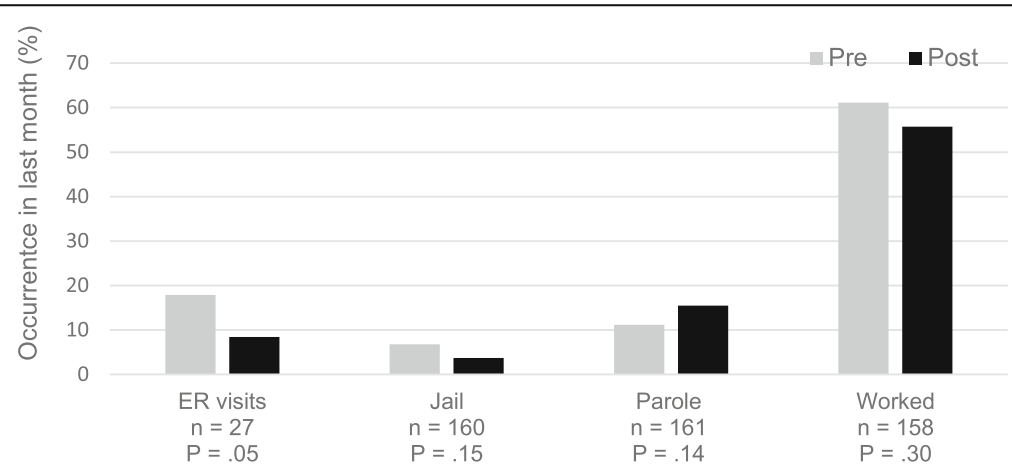

Note. Figure shows the percentage of patients who reported any day of problems in the

previous month, both at baseline (pre) and after 6 months of treatment (post), and SEM,

with $P$ values for changes from baseline (Mc Nemar < .05 = statistically significant); <

.05 = statistically significant). Actual counts per paired variable are noted.

Fig. 3 Change in social issues and services among Colorado Pilot MOUD Program patients.. Note. Figure shows the percentage of patients who reported any day of problems in the previous month, both at baseline (pre) and after 6 months of treatment (post), and SEM, with $P$ values for changes from baseline (Mc Nemar $<.05$ = statistically significant); $<.05=$ statistically significant). Actual counts per paired variable are noted 


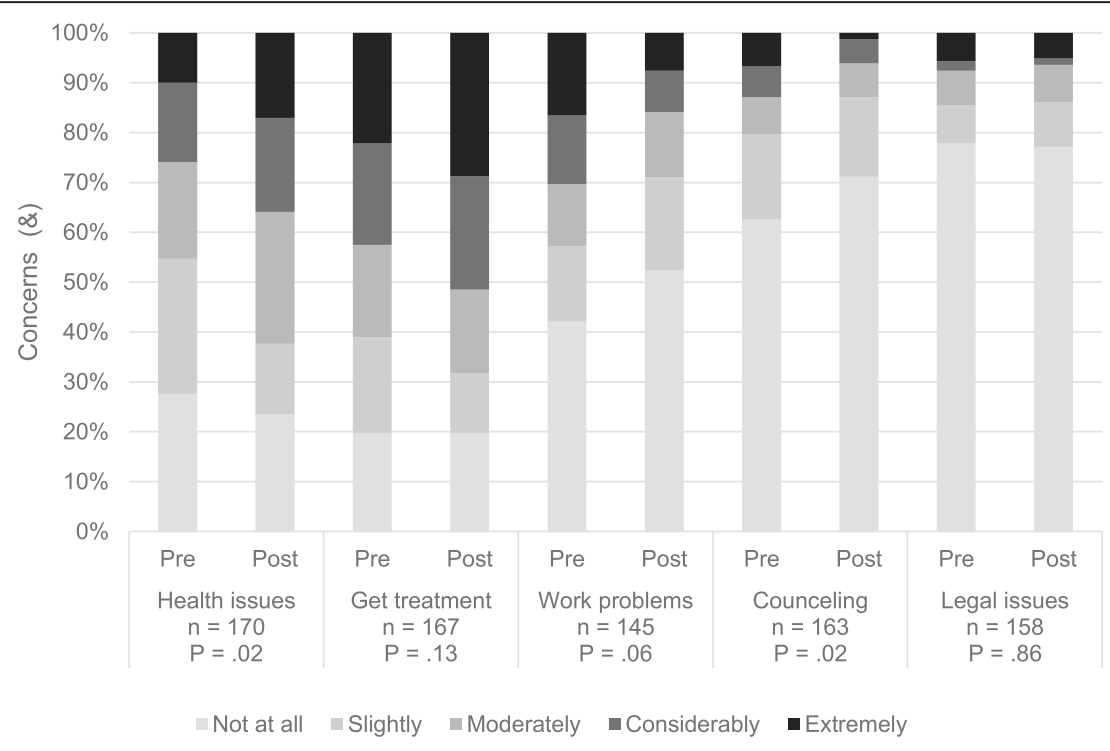

Note. The figure shows patients' concerns regarding health, personal and social issues

before and after MOUD treatment (e.g. "How worried or concerned have you been

about your physical health or any medical problems?") and about getting resources or

counseling to deal with those issues. $P$ values shown changes from baseline $(\mathrm{Mc}$

Nemar-Bowker; $<.05$ = statistically significant). Missing data due to lack of self-

reporting varied by item and actual counts per paired variable are noted.

Fig. 4 Changes in patient perceptions regarding physical health or social concerns. Note. The figure shows patients' concerns regarding health, personal and social issues before and after MOUD treatment (e.g. "How worried or concerned have you been about your physical health or any medical problems?") and about getting resources or counseling to deal with those issues. P values shown changes from baseline (Mc NemarBowker; $<.05$ = statistically significant). Missing data due to lack of self-reporting varied by item and actual counts per paired variable are noted

another challenge clinics faced, and may take many months to develop properly, underscoring the need for grant funding before MOUD can become self-sustaining through fee for service income. Lessons learned for ongoing barriers and facilitators encountered during implementation informed the development of policy to practice of new MAT/MOUD programs.

\section{Discussion}

There is an urgent need to expand access to OUD treatment in rural areas. This program provided access to MOUD treatment to 1005 patients in two rural counties. Our analysis showed that patients who were still in treatment after 6 months had significant reductions in opioid use, alcohol use, and other drug use, as well as improvements in health and employment indicators and clinically meaningful decreases in both anxiety and depression symptoms. These changes have real-life consequences for patients, families, and communities.

\section{Social determinants of health and OUD}

Our data showed that the MOUD services reached a rural patient population with significant life problems related to OUD. A high rate of unemployment was reported among MOUD treatment recipients, 25-fold higher than the average state population [20]. Unemployment has been associated with poorer health outcomes, including greater psychological distress [21] and food insecurity [22], which in turn is linked to adverse mental health outcomes, including suicide [23, 24]. People seeking OUD services presented with moderate mental health issues, physical symptoms, and rates of ER utilization, which is characteristic for this population. OUD is also associated with high rates of medical comorbidities, including HIV risk and Hepatitis C infection $[25,26]$. Because comorbidities can associate to early death in individuals with OUD [26], it is imperative to address them through comprehensive patient care approaches. 
Treatment outcomes on opioid and other substance use Our findings add to previous data showing the efficacy of MOUD, which involves the combination of behavioral therapies with FDA-approved medications as the standard of care for OUD. Treatment offered by clinic sites included methadone delivered by a regulated opioid treatment program as well as buprenorphine and naltrexone used by other outpatient clinics [12]. Consistent with the literature [9], patients in our study who completed $\geq 6$ months of MOUD treatment used opioids and other substances on fewer days, had less health care utilization, and had improved self-reported health compared to their own pre-treatment levels. Alcohol use was also prevalent in this population, especially in combination with other substances. MAT is also a valid treatment for alcohol use disorder [27], and MOUD treatment also had a positive impact on the use of alcohol and sedative analgesics. In contrast, daily usage of marijuana seemed to have increased after 6 months of MOUD treatment. Although outside the scope of this study, patients may use marijuana to cope with pain, anxiety, or other concerns. This finding suggests the importance of screening for cannabis use and underlying reasons for use [28]. A shift in marijuana use during OUD treatment might reveal new challenges due to Colorado's legalization of marijuana [29].

\section{Health outcomes and other opioid related crises}

Patients' health status improved after 6 months of MOUD treatment. Overall, patients reported less concern about their health, but also placed more importance on receiving treatment for health concerns, which might suggest increased motivation for self-management and health maintenance. There also was a significant reduction in patients' concerns about pain, which is a very positive sign. Our findings align with the National Academy of Medicine's recommendations regarding the need for rigorous pain management strategies and tapering doses for enhanced outcomes [30, 31]. Treatment with MOUD drugs has been also shown to decrease OUD-related mortality [32]. Although out of the scope of this study, reductions in substance use has been associated to to fewer opioid overdoses, long-term enhanced quality of life, and reduced mortality among patients who remain in treatment for at least 6 months [33]. While small numbers preclude reaching major conclusions, opioid-related deaths in these two counties indeed dropped from 2017 to 2019 (18.0 vs 14.8 and 20.6 vs no cases per 100,000 people in Pueblo and Routt, respectively) [34].

Chronic pain affects many aspects of a person's daily life, including physical and mental health, family, work, and social relationships [35]. Opioid use can also cause trouble concentrating, maintaining sleep, and depression [36] and pilot Colorado MOUD patients reported high levels of anxiety and depression at the start of treatment. Similar to previous studies, our data demonstrated significant decreases in both anxiety and depression after MOUD treatment. Additionally, because an estimated $20 \%$ of opioid overdose deaths are related to suicide, our results underscore the importance of thorough screening and prompt treatment for mental health concerns [37]. Study sites offered a range of behavioral health treatments [12] which are also linked to improved patient outcomes independent of the type of psychosocial modality offered.

Impaired social functioning and inability to successfully fulfill personal or societal roles are debilitating features of OUD and hallmark criteria for diagnosis [38], Notably, patients who completed 6 months of MOUD treatment also reported an improved ability to function during the prior month. While there were no significant changes in the number of days of paid work, which could reflect in loss of productivity resulting from pain and OUD, patients reported fewer concerns with work related-problems.

\section{Access versus retention in care}

Pilot program grantees advertised their services to prospective OUD patients through partnerships with medical providers in the community, law enforcement agencies, local orgRich RJ, Chou R, Mariano ER, et al. Best Practices, Research Gaps, andanizations, churches, and community groups [12]. Engagement in MOUD treatment has been associated with better patient retention than other OUD treatments [32], superior outcomes, and less relapse [26, 39]. Retention in treatment varies across setting [40]. Although high retention could be achieved at 3 months in academic settings [41], the Colorado MOUD pilot program in rural community clinics had low retention at 6 month, which could be a difference in time of assessment, model of care, study design and setting. While we did not assess the reason for patients leaving the program, published literature suggests that loss to follow up could be due to patients "feeling cured" or having lingering opioid cravings or ongoing pain [39, 42]. Consistent care coordination and a behavioral health component of MOUD is key for retention because it helps patients actively manage their OUD [41, 43]. Equipping providers with modalities like motivational interviewing or mindfulness has proven successful for a variety of conditions ranging from chronic pain management to mental health [44] and has the potential to enhance patient retention.

Societal influences are another potential cause of patient dropout. Despite available treatment, people with mental disorders commonly fail to seek help due to the stigma associated with these services [45]. Our results showed that more clients who dropped out were courtordered to start treatment. Although there were no 
differences in self-reported motivation at the start of treatment, patients who continued might have a combination of true self-determination, commitment to change, and external support. Further studies should explore motivation and the role of social determinants of health and support systems in predicting whether OUD patents remain in treatment. Despite community outreach efforts, opioid-related stigma and negative attitudes are still prevalent, and some still favor withdrawal and detox modalities despite the detrimental effects of these treatment approaches on care retention. Our stakeholderinformed evaluation confirmed that people with OUD are widely stigmatized and stereotyped (unpublished work) which can affect patient functioning [46] and whether patients seek and continue treatment $[10,12]$. These results emphasize a need for ongoing efforts to lower stigma, maintain open door policies for returning to treatment, and resources to maintain a patient registry and to track individuals who fall out of care, given the myriad of factors that contribute to patient success.

\section{Study limitations}

Several limitations are noted. First, we used subjective assessments, which may not be reliable if patients were under detox and having withdrawal symptoms. However, the measures used are similar to accepted processes used in other studies. Second, results are limited to patients still in treatment and providing data. Not all patients lost to follow-up were necessarily treatment failures; some simply may be missing data, which could be partly attributed to voluntary data collection (i.e., clinics not tracking their patients well over time vs patients not returning for care). Because the evaluable patients were demographically and clinically similar to the non-evaluable ones at the start of treatment, the risk of biased results is minimized. Third, the evaluation focused on data from only two rural counties that may not represent other parts of Colorado or of the country. Finally, this study lacked a comparison group, therefore causality cannot be inferred. Likewise, competing explanations like history or maturation effects cannot be ruled out. Moreover, people remaining in treatment might have a stronger motivation at baseline, and those leaving could perceive the treatment was not effective for them, all of which should be further assessed. Our results demonstrate positive outcomes for those patients with evaluable data (remaining in treatment), although we cannot infer about reasons why people remain or drop treatment. As public health impact is limited by retention in care, this should be a primary focus of future studies.

\section{Conclusions}

The ongoing opioid crisis necessitate heightened efforts to implement evidence-based care across the United
States. Health care providers and patients in rural and small towns have limited resources, and both behavioral and social barriers can impede treatment success. The results of this study were part of a multi-pronged statewide effort to address the opioid crisis in both metropolitan and rural, underserved areas. Results also informed expansion efforts to improve the lives of Coloradans with OUD. While more research is needed regarding retention and long-term effects, this study highlights the effectiveness of MOUD as one strategy to address this major public health crisis.

\section{Abbreviations \\ ASI: Addiction severity index (ASI); CU Nursing: University of Colorado College of Nursing; OUD: Opioid use disorders; MOUD: Medication for substance use disorders; MAT: Medication assisted treatment; PHQ-9: Patient health questionnaire (depressive symptoms); GAD-7: The generalized anxiety disorder scale; SPSS: Statistical package for the social sciences}

\section{Supplementary Information}

The online version contains supplementary material available at https://doi. org/10.1186/s13011-021-00424-4

Additional file 1: Supplemental Table 1. Change in substance use from baseline (pre) to 6-months (post) of MOUD treatment.

\begin{abstract}
Acknowledgements
We want to acknowledge all the providers and staff who greatly contribute to this program, especially Erica Whitney, Bella Vigil, for their diligent clinical service, care coordination and data entry, and Samantha Mehring for data coordination. We also want to acknowledge the Colorado Senate for the funding which made possible this project, and the Colorado Consortium of Substance Use Prevention for their ongoing support. Last, we also wish to acknowledge the participants in this study, for their immense courage and resiliency.
\end{abstract}

\section{Authors' contributions}

CRA - Conceptualization; Data curation; Methodology; Formal analysis; Validation; Visualization; Writing - original draft; Writing - review \& editing; TS - Conceptualization; Funding acquisition; Investigation; Project administration; Validation; Writing - review \& editing; MW -

Conceptualization; Funding acquisition; Investigation; Project administration; Supervision; Validation; Writing - review \& editing; AA, NB, UH Investigation; Project administration; Resources; Writing - review \& editing; PFC - Conceptualization; Validation; Methodology; Resources; Supervision; Software; Validation; Visualization; Writing - original draft; Writing - review \& editing. Each author made substantial contributions to the conception of the work, analysis, or interpretation of data. All authors have reviewed and approved the submitted version and agree to be personally accountable for the integrity and accuracy of the work.

\section{Funding}

The program described in this manuscript was funded by the Colorado Senate Bill (SB17-074) Pilot MOUD program from 2017 to 2020, with additional infrastructure support from the Colorado Clinical and Translational Research Center, National Institutes of Health/National Center for Research Resources grant NIH/NCATS Colorado CTSA \# UL1 TR002535 (REDCap). The content is solely the responsibility of the authors and does not necessarily reflect the views of the Colorado Government. 


\section{Declarations}

\section{Ethics approval and consent to participate}

As an evaluation of pilot program implementation, this study was regarded as non-human subjects research by the Colorado IRB (protocol \#19-2217). In compliance with ethical standards for human subject's studies, however, all individual-level data was collected at clinical sites to guide treatment; only aggregated, de-identified was used in this study. Patients had the right to refuse providing data for evaluation. Administrative, site-level data about characteristics of opioid treatment programs was also used as part of the evaluation.

\section{Consent for publication}

Not applicable.

\section{Competing interests}

The authors declare that they have no competing interests.

\section{Author details}

'University of Colorado College of Nursing, 13120 E. 19th Ave, Aurora, CO 80045, USA. ${ }^{2}$ Present address: Rush University College of Medicine, Chicago, IL 60612, USA. ${ }^{3}$ Present Address: Great Lakes Region NIH NIDA CCTN, Chicago, USA. ${ }^{4}$ Health Solutions Inc, 41 Montebello Rd., Pueblo, CO 81001, USA. ${ }^{5}$ Mountain Medical: Road to Recovery, PO Box 773705 , Steamboat Springs, CO 80477, USA. ${ }^{6}$ Colorado Treatment Services, 511 W. 29th St. Pueblo, CO 91008 USA Colorado Treatment Services, Pueblo, CO 91008, USA.

\section{Accepted: 19 November 2021}

\section{Published online: 03 January 2022}

\section{References}

1. Han B, Compton WM, Blanco C, Crane E, Lee J, Jones CM. Prescription opioid use, misuse, and use disorders in U.s. adults: 2015 National Survey on drug use and health. Ann Intern Med. 2017;167(5):293-301. https://doi.org/1 0.7326/M17-0865.

2. Centers for Disease Control and Prevention. Drug overdose deaths. https:// www.cdc.gov/drugoverdose/deaths/index.html Accessed Nov 2021.

3. Hagemeier NE. Introduction to the opioid epidemic: the economic burden on the healthcare system and impact on quality of life. Am J Manag Care. 2018;24(10 Suppl):S200-s206 PMID: 29851449.

4. US Department of Health and Human Services. Facing Addiction in America: The Surgeon General's Report on Alcohol, Drugs, and Health Washington, DC; 2016. https://addiction.surgeongeneral.gov/sites/default/ files/surgeon-generals-report.pdf accessed Nov 2021

5. American Hospital Association. Rural Report. Challenges facing rural communities and the roadmap to ensure local access to high-quality, affordable care. 2019. https://www.aha.org/system/files/2019-02/ruralreport-2019.pdf; accessed Nov 2021

6. Hedegaard, H, and Spencer, M.R, U.S. Department of health and human services. Centers for disease control and prevention. National Center for Health Statistics. Urban-rural differences in trends in overdose deaths varied by type of opioid and over time across the country https://www.cdc.gov/ nchs/data/databriefs/db403-H.pdf; Accessed August 2021.

7. Colorado Health Institute. Miles away from Help. The Opioid Epidemic and Medicaiton-Assisted Treatment in Colorado. 2017. https://www.coloradohea Ithinstitute.org/sites/default/files/file_attachments/2017\%20MAT\%20report. pdf accessed Nov 2021.

8. Colorado Health Institute. The Colorado Health Access Survey: Progress in Peril. 2019.https:/www.coloradohealthinstitute.org/sites/default/files/file_atta chments/CHAS\%20Storybook\%202019\%20for\%20Web.pdf; accessed Nov 2021.

9. Substance Abuse and Mental Health Services Administration. MedicantionAssisted Treatment (MAT) guidance documents. https://www.samhsa.gov/ medication-assisted-treatment; accessed Nov 2021.

10. Andrilla CHA, Moore TE, Patterson DG, Larson EH. Geographic distribution of providers with a DEA waiver to prescribe buprenorphine for the treatment of opioid use disorder: a 5-year update. J Rural Health. 2019;35(1):108-12. https://doi.org/10.1111/jrh.12307.

11. Moore, DJ. Nurse Practitioner's pivotal role in ending the opioid epidemic. J Nurs Pract 2019;15(5):P323-P327, 323, https://doi.org/10.1016/j.nurpra.2019.01.005.

12. Sorrell TR, Weber M, Alvarez A, Beste $N$, Hollins U, Amura CR, et al. From policy to practice: pilot program increases access to medication for opioid use disorder in rural Colorado. J Subst Abus Treat. 2020;114:108027. https:// doi.org/10.1016/j.jsat.2020.108027.

13. McLellan AT, Kushner $H$, Metzger $D$, et al. The fifth edition of the addiction severity index. J Subst Abus Treat. 1992:9(3):199-213. https://doi.org/10.101 6/0740-5472(92)90062-s.

14. Cacciola JS, Alterman Al, Habing B, McLellan AT. Recent status scores for version 6 of the addiction severity index (ASI-6). Addiction. 2011;106(9): 1588-602. https://doi.org/10.1111/j.1360-0443.2011.03482.x.

15. Kroenke K, Spitzer RL, Williams JB. The PHQ-9: validity of a brief depression severity measure. J Gen Intern Med. 2001;16(9):606-13. https://doi.org/10.1 046/j.1525-1497.2001.016009606.x.

16. Dum M, Pickren J, Sobell LC. el al. Comparing the BDI-II and the PHQ-9 with outpatient substance abusers. Addict Behav. 2009;33(2):381-7. https://doi. org/10.1016/j.addbeh.2007.09.017.

17. Spitzer RL, Kroenke K, Williams JB, Löwe B. A brief measure for assessing generalized anxiety disorder: the GAD-7. Arch Intern Med. 2006;166(10): 1092-7. https://doi.org/10.1001/archinte.166.10.1092.

18. Delgadillo J, Payne S, Gilbody S, Godfrey C, Gore S, Jessop D, et al. Brief case finding tools for anxiety disorders: validation of GAD-7 and GAD-2 in addictions treatment. Drug Alcohol Depend. 2012;125(1-2):37-42. https:// doi.org/10.1016/j.drugalcdep.2012.03.011.

19. Harris PA, Taylor R, Thielke R, Payne J, Gonzalez N, Conde JG. Research electronic data capture (REDCap) - a metadata-driven methodology and workflow process for providing translational research informatics support. J Biomed Inform. 2009;42(2):377-81. https://doi.org/10.1016/j.jbi.2008.08.010.

20. U.S. Bureau of Labor Statistics. 2019. https://data.bls.gov/timeseries/LA SST080000000000004?amp\%253bdata_tool=XGtable\&output_view=data \&include_graphs=true. Accessed Sept 2020.

21. Brydsten A, Hammarström A, San SM. Health inequalities between employed and unemployed in northern Sweden: a decomposition analysis of social determinants for mental health. I J Equity Health. 2018;17(1):59. https://doi.org/10.1186/s12939-018-0773-5.

22. Huang J, Kim Y, Birkenmaier J. Unemployment and household food hardship in the economic recession. Public Health Nutr. 2016;19(3):511-9. https://doi.org/10.1017/\$1368980015001603.

23. Milner A, Page A, LaMontagne AD. Cause and effect in studies on unemployment, mental health and suicide: a meta-analytic and conceptual review. Psychol Med. 2014;44(5):909-17. https://doi.org/10.1017/S0033291 713001621.

24. Swendsen J, Conway KP, Degenhardt L, Glantz M, Jin R, Merikangas KR, et al. Mental disorders as risk factors for substance use, abuse and dependence: results from the 10-year follow-up of the National Comorbidity Survey. Addiction. 2010;105(6):1117-28. https://doi.org/10.1111/ j.1360-0443.2010.02902.x.

25. Unick GJ, Rosenblum D, Mars S, Ciccarone D. Intertwined epidemics: national demographic trends in hospitalizations for heroin- and opioidrelated overdoses, 1993-2009. PLoS One. 2013;8(2):e54496. https://doi.org/1 0.1371/journal.pone.0054496

26. National Academies of Sciences, Engineering, and Medicine. Medications for Opioid Use Disorder save lives: consensus study report. Washington, DC: National Academies Press; 2019. https://doi.org/10.17226/25310.

27. Robertson AG, Easter MM, Lin H, Frisman LK, Swanson JW, Swartz MS. Medication-assisted treatment for alcohol-dependent adults with serious mental illness and criminal justice involvement: effects on treatment utilization and outcomes. Am J Psychiatr. 2018;175(7):665-73. https://doi org/10.1176/appi.ajp.2018.17060688.

28. Shams I, Sanger N, Bhatt M, Rosic T, Luo C, Shahid H, et al. The association between health conditions and cannabis use in patients with opioid use disorder receiving methadone maintenance treatment. BJ Psych Open. 2019:5(6):e91. https://doi.org/10.1192/bjo.2019.78.

29. Brooks-Russell A, Ma M, Levinson AH, Kattari L, Kirchner T, Anderson Goodel EM, et al. Adolescent marijuana use, marijuana-related perceptions, and use of other substances before and after initiation of retail marijuana sales in Colorado (2013-2015). Prev Sci. 2019;20(2):185-93. https://doi.org/10.1007/ s11121-018-0933-2.

30. Rich RJ, Chou R, Mariano ER, et al. Best Practices, Research Gaps, and Future Priorities to Support Tapering Patients on Long-Term Opioid Therapy for Chronic Non-Cancer Pain in Outpatient Settings. Natl Acad Med. 2020 https://doi.org/10.31478/202008c

31. National Academy of Medicine. Phillips JK, Ford MA, Bonnie RJ, eds. Pain Management and the Opioid Epidemic: Balancing Societal and Individual 
Benefits and Risks of Prescription Opioid Use. Vol 13. 2017. https://nam.edu/ best-practices-research-gaps-and-future-priorities-to-support-taperingpatients-on-long-term-opioid-therapy-for-chronic-non-cancer-pain-inoutpatient-settings/ Washington (DC): National Academies Press (US). https://www.ncbi.nlm.nih.gov/books/NBK458660/ accessed November 2021.

32. Sordo L, Barrio G, Bravo MJ, Indave Bl, Degenhardt L, Wiessing L, et al. Mortality risk during and after opioid substitution treatment: systematic review and meta-analysis of cohort studies. BMJ. 2017;357:j1550. https://doi. org/10.1136/bmj.j1550

33. Nosyk B, Bray JW, Wittenberg E, Aden B, Eggman AA, Weiss RD, et al. Short term health-related quality of life improvement during opioid agonist treatment. Drug Alcohol Depend. 2015;157:121-8. https://doi.org/10.1016/j. drugalcdep.2015.10.009.

34. Prescription Drug Data Profiles. Colorado Department of Public Health and Environment. https://cdphe.colorado.gov/prevention-and-wellness/injuryprevention/opioid-overdose-prevention/prescription-drug-data. Accessed 2 Jan 2021.

35. Dueñas M, Ojeda B, Salazar A, Mico JA, Failde I. A review of chronic pain impact on patients, their social environment and the health care system. J Pain Res. 2016;9:457-67. https://doi.org/10.2147/JPR.S105892.

36. Hartwell EE, Pfeifer JG, McCauley JL, Moran-Santa Maria M, Back SE. Sleep disturbances and pain among individuals with prescription opioid dependence. Addict Behav. 2014;39(10):1537-42. https://doi.org/10.1016/j.a ddbeh.2014.05.025.

37. Oquendo MA, Volkow ND. Suicide: a silent contributor to opioid-overdose deaths. N Engl J Med. 2018;378(17):1567-9. https://doi.org/10.1056/NEJMp1 801417.

38. American Psychiatric Association. Criteria from American Psychiatric Association. In: Diagnostic and Statistical Manual of Mental Disorders. Fifth ed. Washington, DC; American Psychiatric Association Publishing; https:// www.psychiatry.org/psychiatrists/practice/dsm2013.

39. Williams AR, Barbieri V, Mishlen K, Levin FR, Nunes EV, Mariani JJ, et al. Longterm follow-up study of community-based patients receiving XR-NTX for opioid use disorders. Am J Addict. 2017;26(4):319-25. https://doi.org/1 0.1111/ajad.12527.

40. Timko C, Schultz NR, Cucciare MA, Vittorio L, Garrison-Diehn C. Retention in medication-assisted treatment for opiate dependence: a systematic review. J Addict Dis. 2016;35(1):22-35. https://doi.org/10.1080/10550887.2016.11 00960.

41. Lynch AC, Weber AN, Hedden S, Sabbagh S, Arndt S, Acion L. Three-month outcomes from a patient-centered program to treat opioid use disorder in lowa, USA. Subst Abuse Treat Prev Policy. 2021;16(1):16(8). https://doi.org/1 0.1186/s13011-021-00342-5.

42. Damian AJ, Mendelson T, Agus D. Predictors of buprenorphine treatment success of opioid dependence in two Baltimore City grassroots recovery programs. Addict Behav. 2017;73:129-32. https://doi.org/10.1016/j.addbeh.2 017.05.010.

43. Carroll KM, Weiss RD. The role of behavioral interventions in buprenorphine maintenance treatment: a review. Am J Psychiatr. 2016;174(8):738-747183192-47. https://doi.org/10.1176/appi.ajp.2016.16070792.

44. Blanco C, Volkow ND. Management of opioid use disorder in the USA present status and future directions. Lancet. 2019;393(10182):1760-72. https://doi.org/10.1016/S0140-6736(18)33078-2.

45. Henderson C, Evans-Lacko S, Thornicroft G. Mental illness stigma, help seeking, and public health programs. Am J Public Health. 2013;103(5):77780. https://doi.org/10.2105/AJPH.2012.301056.

46. von Hippel C, Henry JD, Terrett G, Mercuri K, McAlear K, Rendell PG. Stereotype threat and social function in opioid substitution therapy patients. Br J Clin Psychol. 2017;56(2):160-71. https://doi.org/10.1111/ bjc.12128.

\section{Publisher's Note}

Springer Nature remains neutral with regard to jurisdictional claims in published maps and institutional affiliations.

Ready to submit your research? Choose BMC and benefit from:

- fast, convenient online submission

- thorough peer review by experienced researchers in your field

- rapid publication on acceptance

- support for research data, including large and complex data types

- gold Open Access which fosters wider collaboration and increased citations

- maximum visibility for your research: over $100 \mathrm{M}$ website views per year

At BMC, research is always in progress.

Learn more biomedcentral.com/submissions 